\title{
Enamel Remineralization and Dentine Tubules Occlusion by Bioactive Formulations Based on Ion-Doped Nanohydroxyapatite and Precursor Nanoparticles.
}

Andrei Cristian lonescu ( $\square$ andrei.ionescu@unimi.it )

University of Milan

Lorenzo Degli Esposti

Institute of Science and Technology for Ceramics

Michele lafisco

Institute of Science and Technology for Ceramics

Eugenio Brambilla

University of Milan

\section{Research Article}

Keywords: hydroxyapatite and precursor nanoparticles, PXRD, FTIR, and EDS, Ca-P bioactive nanocompounds

Posted Date: November 5th, 2021

DOI: https://doi.org/10.21203/rs.3.rs-998976/v1

License: @) (i) This work is licensed under a Creative Commons Attribution 4.0 International License. Read Full License 


\section{Abstract}

Recent health care products are based on formulations claimed to provide enamel remineralization and dentinal tubules occlusion through calcium-phosphate bioactive nanocompounds (ion-doped hydroxyapatite and precursor nanoparticles). This study aimed to test and characterize for the first time the structure and composition of a representative sample of remineralizing toothpastes and topical mousses available on the market. The enamel remineralization and dentinal tubules occlusion efficacy of tested formulations were investigated in vitro. Formulations were characterized in terms of water- and acid-insoluble fractions, and PXRD, FTIR, and EDS analyses were performed to determine their composition and investigate the presence of bioactive compounds and doping elements. All formulations containing Ca-P bioactive nanocompounds showed remineralizing ability, notably when hydroxyapatite and amorphous calcium phosphate compounds were doped with small amounts of $\mathrm{CO} 3-, \mathrm{F}, \mathrm{Mg}$, and Sr. Topical mousse formulations showed a higher tubules occlusion capability than toothpastes, independently from their composition. In conclusion, all tested formulations could express remineralizing potential both on enamel and dentin thanks to the presence of biomimetic Ca-P compounds. The presence of doping elements or CPP-ACP seems essential to allow such performances.

\section{Introduction}

Enamel demineralization is the primary mechanism involved in the etiopathogenesis of dental caries and erosion [1]. When the oral microenvironment reaches low pH values (i. e., lower than the critical pH of dental surfaces), the demineralization process is triggered. This phenomenon represents the outcome of very complex biological and chemical interactions at the interface between the external oral environment, the biofilm colonizing hard tissues, and the dental hard tissues themselves[2,3]. Hydroxyapatite ( $\mathrm{HA})$ is the main component of dental enamel, whichis soluble in acidic solutions and has a critical pH of about 5.5.Dentine, having a lower mineral content, showsan even higher critical pH (about 6.2) due to its lower crystallinity. Below these $\mathrm{pH}$ values, an ionic imbalanceprogressively causes the loss of ionic species from the hard tissues and the consequent dissolution of the tissue itself [4]. Several factorscan cause a pH drop to values much lower than 5.5 and trigger dental demineralization, such as the fermentative activity of dental biofilms, the intake of acidic food or beverages, and gastroesophageal reflux $[5,6]$. In physiological conditions, salivary ion content and buffering capacity can compensate for the demineralization process, thus creating a delicate equilibrium where demineralization and remineralization phases occur, resulting in an even ionic balance [7].

Changes in the oral microenvironment, such as a significant increase in carbohydrate intake, can impair this equilibrium and favor demineralization [3]. Therefore, an external supply of calcium and phosphate ions was proposed to shift the equilibrium towards remineralization.

Demineralization is a reversible process. When the microenvironment reaches $\mathrm{pH}$ values higher than 7.0 ,and there is an availability of calcium and phosphate ions, remineralization can occur. Such ions precipitate, covering the dental surfaces withan amorphous mineral layer. Under defined conditions, however, this layer can act as a precursor to form a more organized mineral structure[8-10]. This phenomenon is called epitaxial growth. It was demonstrated that impaired enamel hydroxyapatite prisms could guide epitaxial growth, starting a biomineralization process to restore demineralized hard tissues [11,12]. Toothpastes and, more recently, topical formulations (mousses) are an effective and reliable way to deliver active principles to dental hard tissues, notwithstanding differences in their application protocols. Such topical formulations were developed to provide a relatively high delivery of ionic species to hard tissues during prolonged contact, for instance, by using trays. Therefore, the inclusion of compounds with remineralizing capabilities in toothpaste and topical formulations has become a common practice nowadays.[13,14].

Among these compounds, the use of fluoride is still considered the gold standard in the inhibition of demineralizing processes $[15,16]$. This ion has a dual anti-caries activity duetothe partial or total substitution of hydroxyl groups of HA, thus forming the more acid-resistant fluorapatite and directly inhibiting the metabolic pathways of microbial cells in the overlying biofilm. 
Consequently, fluoride-treated dental tissues show increased resistance to demineralization since fluorapatite has a lower critical pH than HA. Also, biofilms' acidogenicity decreases.

Synthetic HA and other calcium phosphate-based systems such as amorphous calcium phosphate (ACP) particles and especially nanoparticles were shown to promote remineralization processes $[17,18]$. Furthermore, the doping of HA with ions, such as carbonate, $\mathrm{Zn}^{2+}, \mathrm{F}^{-}, \mathrm{Mg}^{2+}$, and $\mathrm{Sr}^{2+}$ has been shown to modulate the crystals' nucleation, growth, orientation, and solubility. In fact, biogenic dentalHA contains small amounts of ions such as $\mathrm{CO}_{3}{ }^{2-}, \mathrm{Mg}^{2+}$, and $\mathrm{Sr}^{2+}$, having the same effects[10,18]. ACP was shown to release significantly higher amounts of calcium and phosphate ions than other CaP phases, including HAp, as ACP is the most soluble CaP phase. However, ACP is a metastable material that is quickly converted to more stable CaP phases when in contact with water or moisture and represents the transient phase of natural HAp formation [19]. Several formulations have been proposed to stabilize ACP for enamel remineralization, among which the most common are casein phosphopeptides (CPP) [20] and, more recently, citrate (Cit-ACP)[10].

Both HAp and ACP found successful application as active ingredients for remineralizing toothpastes and remineralizingtopical formulations.Several products that claim a remineralizing effect containing these calcium phosphates phasesin the form of stabilized nanoparticles are sold worldwide as over-the-counter products.

This work aimed to compare the chemical and physical composition and in vitrobioremineralization activityof five commercially-available toothpaste and topical formulations containing ion-substituted HA, Cit-ACP, or CPP-ACP with a conventional fluoride-containing toothpaste, kept as a reference.

The null hypothesis was that the remineralization activity of the tested toothpastes is not significantly different from that of a fluoride-containing conventional toothpaste used as control.

\section{Results And Discussion}

The formulations tested in this study and their ingredients as specified by the manufacturers are illustrated in Table 1. First,the water content was estimated as weight difference after desiccation through freeze-drying in each formulation. Then, the waterinsoluble fractionwas obtained by repeated washings of the dried materials with distilled water, and eventually, the acidinsoluble fraction, representing the total silica content, was determined by acid treatment of the water-insoluble fraction [17]. The water-insoluble and acid-insoluble specimens were characterized by powder X-ray diffraction (PXRD) and Fourier transform infrared (FTIR) spectroscopy. Compositional analysis was performed to identify the content of $\mathrm{Ca}, \mathrm{P}, \mathrm{Mg}, \mathrm{Sr}, \mathrm{Si}$, and F. After that, an in vitro analysis on human molars evaluated the efficacy of each toothpaste on remineralizing enamel and occluding dentinal tubules in a setting as close as possible to in vivo conditions. Compositional analysis was performed on molar specimens after toothpaste treatment.

Table 1. Specified ingredients of the tested toothpastes and mousses. The remineralizing ingredients, including the sources of fluoride ions, are highlighted in bold. 


\begin{tabular}{llll}
$\begin{array}{l}\text { Formulation } \\
\text { type }\end{array}$ & Name (abbrv.) & Company & Specified ingredients \\
\hline $\begin{array}{l}\text { Toothpaste } \\
\text { formulation }\end{array}$ & $\begin{array}{l}\text { Biosmaltocaries } \\
\text { abrasion and } \\
\text { erosion }\end{array}$ & $\begin{array}{l}\text { Curaden } \\
\text { Healthcare } \\
\text { S.p.A. }\end{array}$ & $\begin{array}{l}\text { Aqua, glycerin, hydrated silica, fluoride-hydroxyapatite (1450 ppm F), } \\
\text { Mg-Sr-carbonate hydroxyapatite conjugated with chitosan, cellulose } \\
\text { gum, xylitol, cocamidopropyl betaine, xantham gum, aroma, acesulfame } \\
\text { K, ethylhexylglycerin, phenoxyethanol, sodium benzoate, citric acid. }\end{array}$ \\
& $\begin{array}{l}\text { (BT) } \\
\text { Saronno } \\
\text { (VA), Italy }\end{array}$ & \\
\hline
\end{tabular}

\begin{tabular}{|c|c|c|c|}
\hline $\begin{array}{l}\text { Toothpaste } \\
\text { formulation }\end{array}$ & $\begin{array}{l}\text { Biorepair Plus } \\
\text { (RT) }\end{array}$ & $\begin{array}{l}\text { Coswell } \\
\text { Funo (BO), } \\
\text { Italy }\end{array}$ & $\begin{array}{l}\text { Aqua, zinc carbonate hydroxyapatite, glycerin, sorbitol, hydrated silica, } \\
\text { silica, aroma, cellulose gum, tetrapotassium pyrophosphate, sodium } \\
\text { myristoyl sarcosinate, sodium methyl cocoyl taurate, sodium saccharin, } \\
\text { citric acid, phenoxyethanol, benzyl alcohol, sodium benzoate. }\end{array}$ \\
\hline
\end{tabular}

$\begin{array}{llll}\begin{array}{c}\text { Toothpaste } \\ \text { formulation }\end{array} & \begin{array}{l}\text { Colgate triple } \\ \text { action }\end{array} & \begin{array}{l}\text { Colgate- } \\ \text { Palmolive, } \\ \text { Guilford, UKK }\end{array} & \begin{array}{l}\text { Aqua, sorbitol, hydrated silica, glycerin, sodium lauryl sulfate, PEG-12, } \\ \text { peppermint oil, spearmint oil, cellulose gum, NaF (1450 ppm F), sodium } \\ \text { saccharin, Cl 74160, Cl 74260, TiO2. }\end{array}\end{array}$

\begin{tabular}{lll} 
(reference) & $(\mathrm{CT})$ & \\
$\begin{array}{l}\text { Topical } \\
\text { formulation } \\
\text { (mousse) }\end{array}$ & $\begin{array}{l}\text { Biosmalto } \\
\text { Caries }\end{array}$ & Curaden \\
\hline
\end{tabular}

$\begin{array}{lll}\begin{array}{l}\text { Topical } \\ \text { formulation }\end{array} & \begin{array}{l}\text { Biorepair } \\ \text { desensitizer }\end{array} & \text { Coswell } \\ \text { (mousse) } & \text { enamel repair } & \end{array}$

(mousse) enamel repair

$\begin{array}{llll}\begin{array}{l}\text { Topical } \\ \text { formulation } \\ \text { (mousse) }\end{array} & \text { MI Paste Plus } & \text { GC } & \begin{array}{l}\text { Aqua, Recaldent }{ }^{\mathrm{m}} \text { (10\% CPP-ACP), fluoride (900 ppm F), glycerol, d- } \\ \text { Corporation, } \\ \text { sorbitol, CMC-Na, propylene glycol, silicon dioxide, titanium dioxide, }\end{array} \\ & (\mathrm{MM}) & \begin{array}{l}\text { Tokyo, } \\ \text { Japlitol, phosphoric acid, flavoring, sodium saccharin, ethyl p- } \\ \text { hydroxybenzoate, propyl p-hydroxybenzoate, butyl p-hydroxybenzoate. }\end{array}\end{array}$

Structural characterization The amount of water was estimated as the weight difference between the whole product and the material collected after freeze-drying. The water-insoluble fraction was extracted from the products through an aqueous washing step by centrifugation. In addition, in this fraction, we have discriminated the calcium phosphate phase from the silica-based one by using a mildly acidic washing since only calcium phosphate is soluble in acid.

All toothpastes contain 15 - 20 wt.\% water-insoluble inorganic matter, 20 - 40 wt.\% water-soluble matter, and 40 - 50 wt.\% water (Table 2). Among the toothpastes, only BT and RT have an acid-soluble inorganic phase, while CT contains acidinsoluble silica and titanium dioxide, in agreement with the ingredients list. BT and RT have a different weight ratio between calcium phosphate and silica, namely RT contain 15 wt.\% of calcium phosphate and 9 wt.\% of silica (ratio CaP: silica $=1.7$ ) while BTpresents $5 \mathrm{wt} . \%$ of calcium phosphate and $10 \mathrm{wt} . \%$ of silica (ratio CaP : silica $=0.5$ ).

Taking into account topical formulations, RM has the highest water content, the lowest water-soluble matter content, and it hasa higher amount of calcium phosphate than silica. On the contrary, BMcontains the lowest amount of water and the highest content of water-soluble matter. According to the manufacturer's specifications,BM is a water-free product.Since the water content of the tested formulations was calculated as weight difference after freeze-drying, the water content detected in BMmight be due to moisture and volatile components. BM, differently from RM, contains more silica than calcium phosphate. MMhas a peculiar composition made by a low amount of water-insoluble components (ca. $1 \mathrm{wt} . \%$ calcium phosphate and 3 wt.\% silica) and ca. $95 \%$ of weight made by water and water-soluble ingredients.

The water-insoluble component of the products before and after washing with the acid solution was analyzed by PXRD (Fig. 1). The PXRD patterns of the water-insoluble phase of BT and RTs have similar diffraction patterns (Fig. 1), showing a broad band centered at $23^{\circ}$ that corresponds to amorphous silica [21] and several diffraction peaks that were indexed as HA, as shown by Hughes et al. (PDF card file 09-0432, relative crystallographic planes as reported in [22]). 
Table 2. Composition of each tested formulation resulting from freeze-drying, water-washing and acid-washing procedures. Superscript (a), data published in Degli Esposti et al. [17]

\begin{tabular}{lllll} 
Formulation & Water(wt\%) & Water-soluble fraction(wt\%) & \multicolumn{2}{l}{ Water-insoluble fraction(wt\%) } \\
\hline & & & Calcium phosphate (wt\%) & Silica (wt\%) \\
\hline BT & $52 \pm 7^{\mathrm{a}}$ & $33 \pm 3^{\mathrm{a}}$ & $5.0 \pm 0.5^{\mathrm{a}}$ & $10 \pm 1^{\mathrm{a}}$ \\
\hline RT & $55 \pm 1$ & $22 \pm 1$ & $15 \pm 1$ & $9 \pm 1$ \\
\hline CT (reference) & $41 \pm 1$ & $42 \pm 2$ & $0 \pm 0$ & $17 \pm 1$ \\
\hline BM & $10 \pm 1$ & $78 \pm 1$ & $2.0 \pm 0.5$ & $10 \pm 1$ \\
\hline RM & $63 \pm 1$ & $11 \pm 1$ & $20 \pm 1$ & $6 \pm 1$ \\
\hline MM & $54 \pm 1$ & $42 \pm 3$ & $1.0 \pm 0.1$ & $3.0 \pm 0.5$
\end{tabular}

The intensity of the silica band in comparison to the intensity of HA peaks is higher in BTthan in RT, in agreement with the higher silica content evaluated by compositional analysis. The HA peaks are broadened in both toothpastes, indicating a poor crystallinity and a high similarity of the material to biogenic HA [23]. After the acidic washing of both toothpastes, the HA peaks disappear, which confirms that the process successfully removes the calcium phosphates components. In the PXRD patterns of the referenceCT, the band of amorphous silica is present, together with weak diffraction peaks that were indexed as anatase $\left(\mathrm{TiO}_{2}\right.$, PDF card file 21-1272), and there are no changes after acidic washing, confirming that no calcium phosphates are present in the control product.

The PXRD pattern of the water-insoluble fraction of BM shows amorphous silica and HA peaks, with the latter being relativelylow and broad. It must be considered that BM does not contain $\mathrm{HA}$, rather than calcium phosphate carbonate citrate fluoride as per manufacturer's specifications, that is, Cit-ACP. There is a general agreement that ACP crystallizes and converts into HA in the presence of water [10].Therefore, the presence of HA in the water-insoluble fraction can be expected due to CitACP crystallization during the washing process. Also, the PXRD pattern of the water-insoluble fraction of RMpresents silica and HA peaks, but compared with BM, the HA peaks are more intense and resolved. This finding suggests that RM has a higher HA content in agreement with compositional analysis, and its HA has a higher crystallinity. The PXRD pattern of the water-insoluble phase of $\mathrm{MM}$ is dominated by anatase diffraction peaks, while amorphous silica and HA signals were also observed (Fig. 1, MM water-washed and acid-washed). As for BM, the washing process has likely converted the ACP contained as CPP-ACP into HA. For all topical formulations, the HA peaks are not present in the PXRD patterns of the acid-insoluble fractions, confirming the removal of calcium phosphate thanks to the acidic washing.

The products were also investigated by FT-IR spectroscopy. The FT-IR spectra of the freeze-dried whole formulations, the waterinsoluble fractions, and the acid-insoluble fractions were collected (Fig. 2). In the case of BM and MM, the freeze-drying did not yield a dry product but formed a thick paste, and therefore for these samples, the FT-IR of the whole product could not be collected. In general, the spectra of the whole products are of complex interpretation due to the superposition of vibrational bands of silica, calcium phosphates, and organic molecules. Some components were removed with the aqueous and acidic washings, allowing to associate the IR peaks of each phase better.

The FT-IR spectra of the water-insoluble fraction of BT and RT present the same bands. The main bands are due to silica and fall at ca. $455 \mathrm{~cm}-1$ and $1055 \mathrm{~cm}^{-1}$, which are associated with the $\mathrm{Si}-0$ rocking and the Si-O-Si siloxane vibration, respectively [24]. In addition, a weak band present at ca. $800 \mathrm{~cm}^{-1}$ is diagnostic of amorphous silica [24]. These samples also present two bands at 603 and $565 \mathrm{~cm}^{-1}$ due to the bending vibration of $\mathrm{HA}$ phosphate groups $\left(\mathrm{v}_{4} \mathrm{PO}_{4}\right.$ mode) [25]. Furthermore, the $\mathrm{Si}-\mathrm{O}-\mathrm{Si}$ bands of these two toothpastes present a shoulder at $1040 \mathrm{~cm}^{-1}$ that is attributed to the v3PO4 band (phosphate stretching vibration) of $\mathrm{HA}$. Also, the intensity ratio between $\mathrm{Si}-\mathrm{O}-\mathrm{Si}$ and $\mathrm{v}_{4} \mathrm{PO}_{4}$ bands suggests that $\mathrm{RT}$ has a higher $\mathrm{HA}$ : silica ratio than BT. In the BT and RTs spectra, there are three weak bands at ca. $870 \mathrm{~cm}^{-1}, 1415 \mathrm{~cm}^{-1}$, and $1460 \mathrm{~cm}^{-1}$ 
belonging to the bending and stretching vibrations of carbonate groups that substitute the phosphate groups of HA (carbonate substitution type B) [25]. Such a finding confirms the carbonate doping of HA as reported in the ingredients list of the toothpastes (Table 1).In the spectra of the acid-treated BT and RT the phosphate and carbonate bands are no more present, confirming that the acidic washing has removed the HA phase and its carbonate doping. A new peak at $1385 \mathrm{~cm}^{-1}$ associated with $\mathrm{v}_{3} \mathrm{NO}_{3}$ vibration of nitrate ions [26] is present in the spectra of all acid-treated samples that can be attributed to the nitrate ions adsorbed on silica after $\mathrm{HNO}_{3}$ treatment.

The FT-IR spectrum of the acid-insoluble fraction of the reference CT only shows the bands associated with silica, in agreement with PXRD analysis, and is identical to the spectrum of the water-insoluble fraction. The FT-IR spectrum of the water-insoluble fraction of BM shows the bands associated with silica, phosphate, and carbonate. However, in this formulation, the phosphate bands are weaker than those of silica, in agreement with the lower calcium phosphate content of the product. Furthermore, the $\mathrm{v}_{4} \mathrm{PO}_{4}$ band is split into two sub-bands at 603 and $565 \mathrm{~cm}^{-1}$, this splitting being typical of a crystalline HA [25]. This finding further confirms the fact thatthe aqueous washing has induced the crystallization of ACP.The water-insoluble fraction of RMpresents the same FT-IR bands shown in the water-insoluble fraction of BM. However,its phosphate and carbonate bands are more intense thanBM, in agreement with the compositional analysis.

Finally, the FT-IR spectrum of the water-insoluble MMfraction (Fig. 2) presents the bands associated with silica and phosphate, along with a band at ca. $680 \mathrm{~cm}^{-1}$ that is due to the $0-\mathrm{Ti}-\mathrm{O}$ vibration of anatase [27]. As seen with BM, the phosphate band in this spectrum is split, suggesting the presence of crystallineHA, likely formed by water-mediated crystallization of ACP. As seen in PXRD patterns, the phosphate and carbonate FT-IR bandsare not present inthe acid-insoluble fractions of the three topical formulationsbecause the acidic washing has removed calcium phosphate compounds.

Compositional Analysis. The content of $\mathrm{Mg}^{2+}, \mathrm{Sr}^{2+}, \mathrm{Zn}^{2+}$, and $\mathrm{F}^{-}$ions in the whole products and water-insoluble fractions was determined usinginductively coupled plasma atomic emission spectrometer (ICP-OES) and ion-selective electrode (ISE) methods(Table 3). We have focused on these ions since, according to the literature, they are involved in remineralizing [28,29] and antibacterial activity [30,31]. The total fluorine content of the products is in good agreement with the declared values of $\mathrm{BT}$ and $\mathrm{BM}(1450 \pm 50 \mathrm{ppm})$ while it was a little low (about $-20 \%)$ compared to the declared values of the reference (CT, $1450 \pm$ $50 \mathrm{ppm})$ and $\mathrm{MM}(900 \pm 50 \mathrm{ppm})$. As reported in the ingredients list, RT and RM do not contain fluoride. BT contains both $\mathrm{Mg}^{2+}$ and, especially, $\mathrm{Sr}^{2+}$ ions in the water-insoluble fraction. Besides, $\mathrm{RT}$ contains a limited amount of $\mathrm{Mg}^{2+}$ and has a high amount of $\mathrm{Zn}^{2+}$ in the water-insoluble fraction. RM contains low amounts of $\mathrm{Mg}^{2+}$ and a high amount of $\mathrm{Zn}^{2+}$. BMcontains a very high amount of $\mathrm{Sr}^{2+}$ as strontium acetate, according to the manufacturer.

An aliquot of $1 \mathrm{~g}$ of eachformulation (whole product) was also assessed by energy-dispersive X-ray spectrometry (EDS) after vacuum-drying in a vacuum bell overnight, then inside a scanning electron microscope (SEM) chamber. The probe provided results on the surface elemental composition of the formulations' dry mass (Table 4).

The results are generally in good keeping with the previous analysis. EDS showed a generally similar carbon content in BT, RT, $\mathrm{BM}$, and RM, while in higher amounts in CT and MM. It was shown that the topical formulations (BM, RM) showed higher Ca and $\mathrm{P}$ content than their corresponding toothpaste counterparts (BT, RT). An exception was MM that contained surprisingly low $\mathrm{Ca}$ and $\mathrm{P}$. The latter finding can be explained by the bioactive compound present as CPP-ACP. The casein phosphopeptide is a nanocomplex acting as a reservoir for calcium and phosphate ions [32], thus explaining, at the same time, a relatively high carbon presence (peptide chain) and a relatively low $\mathrm{Ca}$ and $\mathrm{P}$ presence in the tested formulation.Silicon content correlated with the silica content measured in the water-insoluble and acid-insoluble fraction.

Regarding the doping ions present in small amounts or traces, Mg was correctly detected when in its highest amount (BT), while the analysis did not identify its presence in RT and RM. The amounts of F, Zn, and Sr correlated with the ICP-OES and ISE results. The CT and MM water- and acid-insoluble fractions wereconfirmed by EDS as containing low amounts of titanium, while all tested formulations contained traces of aluminum that were twice as high in toothpastes than in topical formulations. 
From the point of view of the analytic technique, EDS can provide a complete elemental profile of the tested formulations, even when elements were present in traces (less than $\approx 1 \mathrm{wt} \%$ ). It has to be kept in mind that the observation was performed on the outer part of a dry mass, whose composition might be slightly different from its bulk.

Remineralization properties of the tested formulations on human enamel. The efficacy of the formulations as enamel remineralizing agents was tested on human dental enamel specimens that were preliminarily demineralized with $37 \mathrm{wt} \%$ $\mathrm{H}_{3} \mathrm{PO}_{4}$ following a well-established protocol [10]. After acid etching, negative control samples showed the prismatic structure made by native HA crystals that constitute the primary enamel prisms unit, as etching procedures dissolved the superficial amorphous layer. A demineralization pattern was identified, mainly dissolving the interprismatic mineral phase. The storage solution, only containing phosphate ions, was unable to remineralize enamel structures. On the contrary, all tested formulations excepting the reference toothpaste showed remineralization of the demineralized enamel substrate (Figure 3).Through synoptic comparison of control and treated specimens, it is evident that the repeated application of the formulations for one week has led to the remineralization of the eroded enamel in all tested formulations by depositing a new crystalline phase in direct contact with the pristine one. Epitaxial growth of nanocrystallites was identified that was most pronounced in $\mathrm{BT}, \mathrm{BM}$, and MM compared to RT and RM. This different effect could be possibly due to the presence of the doping ions

$\left(\mathrm{Mg}^{2+}, \mathrm{Sr}^{2+}\right.$, and especially $\left.\mathrm{F}^{-}\right)[33,34]$. The fluoride-containing toothpaste(reference $\left.\mathrm{CT}\right)$ showed an even deposition of an amorphous layer on enamel surfaces, which could be due to silica deposition from the toothpaste or amorphous calcium fluoride. No signs of epitaxial growth were identified in these specimens.

Table 3. $\mathrm{Mg}^{2+}, \mathrm{Sr}^{2+}, \mathrm{Zn}^{2+}$, and $\mathrm{F}^{-}$content in the whole formulations and the water-insoluble fractions.

$\mathrm{Mg}, \mathrm{Sr}$, Zn were quantified by inductively coupled plasma atomic emission spectrometer (ICP-OES), while $\mathrm{F}$ was quantified by the ion-selective electrode (ISE) method.

\begin{tabular}{|c|c|c|c|c|c|}
\hline Formulation & Phase & $\mathrm{Mg}(\mathrm{ppm})^{\mathrm{a}}$ & $\operatorname{Sr}(p p m)^{a}$ & $\mathrm{Zn}(\mathrm{ppm})^{\mathrm{a}}$ & $F(p p m)^{b}$ \\
\hline \multirow[t]{2}{*}{ BT } & Whole product & $200 \pm 100^{c}$ & $900 \pm 100^{c}$ & - & $1458 \pm 25^{c}$ \\
\hline & Water-insoluble fraction & $2000 \pm 100^{c}$ & $7200 \pm 100^{c}$ & - & - \\
\hline \multirow[t]{2}{*}{ RT } & Whole product & $110 \pm 50$ & - & $1800 \pm 50$ & - \\
\hline & Water-insoluble fraction & $440 \pm 90$ & - & $6600 \pm 300$ & - \\
\hline \multirow[t]{2}{*}{ CT (reference) } & Whole toothpaste & - & - & - & $1185 \pm 34$ \\
\hline & Water-insoluble fraction & - & - & - & - \\
\hline \multirow[t]{2}{*}{ BM } & Whole product & - & $12000 \pm 1000$ & - & $1300 \pm 16$ \\
\hline & Water-insoluble fraction & - & $22000 \pm 2000$ & - & - \\
\hline \multirow[t]{2}{*}{ RM } & Whole product & - & - & $1390 \pm 10$ & - \\
\hline & Water-insoluble fraction & $610 \pm 90$ & - & $5100 \pm 400$ & - \\
\hline \multirow[t]{2}{*}{ MM } & Whole product & - & - & - & $731 \pm 33$ \\
\hline & Water-insoluble fraction & - & - & - & - \\
\hline
\end{tabular}

Table4.Energy-dispersive X-ray spectroscopy (EDS) compositional analysis of the surface layer $(\approx 1 \mu \mathrm{m})$ of $1 \mathrm{~g}$ aliquot of each toothpaste tested in the present study. 


\begin{tabular}{lllllll} 
wt\% & BT & RT & CT (reference) & BM & RM & MM \\
\hline $\mathrm{C}$ & 25.53 & 26.08 & 31.29 & 24.62 & 23.96 & 39.55 \\
\hline $\mathrm{O}$ & 42.69 & 43.75 & 48.83 & 36.76 & 34.19 & 47.37 \\
\hline $\mathrm{P}$ & 4.93 & 4.95 & 0.00 & 5.82 & 8.04 & 1.96 \\
\hline $\mathrm{Ca}$ & 9.80 & 12.12 & 0.00 & 14.18 & 20.79 & 3.92 \\
\hline $\mathrm{F}$ & 0.18 & 0.00 & 0.30 & 0.20 & 0.00 & 0.20 \\
\hline $\mathrm{Mg}$ & 0.35 & 0.00 & 0.00 & 0.00 & 0.00 & 0.00 \\
\hline $\mathrm{Zn}$ & 0.00 & 0.27 & 0.00 & 0.00 & 0.22 & 0.00 \\
\hline $\mathrm{Sr}$ & 0.93 & 0.00 & 0.00 & 3.79 & 0.00 & 0.00 \\
\hline $\mathrm{Na}$ & 1.38 & 1.09 & 0.89 & 0.73 & 3.27 & 1.83 \\
\hline $\mathrm{Al}$ & 0.32 & 0.29 & 0.02 & 0.15 & 0.16 & 0.17 \\
\hline $\mathrm{Si}$ & 12.12 & 9.36 & 17.15 & 11.52 & 6.22 & 2.08 \\
\hline $\mathrm{S}$ & 0.30 & 0.25 & 0.00 & 0.07 & 1.88 & 0.14 \\
\hline $\mathrm{Cl}$ & 1.08 & 0.30 & 0.00 & 0.57 & 0.12 & 0.28 \\
\hline $\mathrm{K}$ & 0.92 & 1.56 & 0.00 & 1.21 & 1.01 & 0.0 \\
\hline $\mathrm{Ti}$ & 0.00 & 0.00 & 1.52 & 0 & 0.00 & 2.39 \\
\hline $\mathrm{Ca} / \mathrm{P}(\mathrm{mol})$ & 1.54 & 1.89 & - & 1.88 & 2.00 & 1.54 \\
\hline & & & & & & \\
\hline
\end{tabular}

Dentinal tubuli occlusion by the tested formulations. The negative control(PBS) showed that all tubulesexposed by the demineralization procedure remained open.The reference treatment (CT) showed the occlusion of very few tubules. In contrast, all tested topical formulations showed complete occlusion of the dentinal tubules, while the toothpastes could occlude the majority of the exposed tubules(Figure 4). An amorphous mineral layer could be identified on the surface of the specimens, occluding the tubules opening.

To measure the thickness of the deposited layer, it was beamed with the electron gun while sequentially focusing it on the opening of single tubules. It was observed that, due to its reduced thickness, the layer collapsedafter few minutes, exposing the tubule lumen (Figure 5). It is likely that carbon-rich collagen structures underneath the tubule opening were denatured by heating with the electron gun, thus collapsing. Therefore, it was possible to show that the layer had a thickness of about 200 $\mathrm{nm}$ in all remineralizing formulations. Beaming the layer that was deposited on the intertubular dentine produced no effect.

Elemental surface analysis of treated enamel specimens. Energy-dispersive X-Ray Spectroscopy (EDS) as the surface compositional analysis was carried out on enamelspecimens treated with the different formulations to study their surface elemental composition(Table 5). The enamel negative control specimens showed the presence of $\mathrm{C}, \mathrm{Ca}, \mathrm{P}, \mathrm{Na}, \mathrm{Mg}$, and $\mathrm{Cl}$. The presence of Si traces can be explained by the polishing procedures performed, despite thorough cleaning and acid treatment. The Ca/P molar ratio was $1.91 \pm 0.02$, which is typical of enamel HA [38,39]. Specimens treated with Biosmalto and RTs showed the presence of the same elements and had a similar $\mathrm{Ca} / \mathrm{P}$ ratio $(1.91-1.95 \pm 0.05)$.

Traces of F and Sr were detected on BT- and BM-treated surfaces, while Zn was detected on RT- and RM-treated ones. The increased presence of Si on RT and RM-treated surfaces compared to the negative control and the presence of $\mathrm{F}, \mathrm{Sr}$, and $\mathrm{Zn}$ indicated that a new mineral phase had been deposited on eroded enamel. This new mineral phase had a similar chemical composition to biogenic apatite (including the degree of carbonated HA) enriched with the doping ions and containing traces 
of silica derived from the toothpastes. The tested mousses deposited a surface layer with a relatively higher molar ratio (2.05$2.01 \pm 0.03)$. F and Si content of the layer formed after BM treatment was significantly higher compared to BT. The other doping ions were present in similar amounts to the toothpastes.

The specimens treated with the reference toothpaste showed the deposition of significant amounts of $\mathrm{F}$ and Ti. In particular, $\mathrm{F}$ presence was significantly lower compared to specimens treated with BT and mousse.

The acquired data represented the elemental composition of the $\approx 1 \mu \mathrm{m}$ superficial layer. Since the thickness of the deposited remineralization layer was found to be 200 to $300 \mathrm{~nm}$ (Figure 5), it can be inferred that the signal provided by the EDS probe is composed of information coming from both the remineralized layer and the underlying substrate to a varying amount, depending on the atomic number of the assessed element (Figure 6). The absolute values of elemental composition have, therefore, to be interpreted with the necessary caution. Indeed, the analysis was performed to confirm that the remineralized layer originated from the tested formulation whenever observed on the specimens' surface.

Table 5. Energy-dispersive X-ray spectroscopy (EDS) compositional analysis of enamel surface layer $(\approx 1 \mu \mathrm{m})$ brushed with the tested formulations. Different superscript letters indicate, for each element, significant differences between formulation treatments effect on the enamel surfaces.

\begin{tabular}{|c|c|c|c|c|c|c|c|}
\hline$w t \%$ & BT & RT & $\begin{array}{l}\text { CT } \\
\text { (reference) }\end{array}$ & BM & RM & MM & $\begin{array}{l}\text { Negative } \\
\text { control } \\
\text { (PBS) }\end{array}$ \\
\hline C & $6.23(1.13)^{\mathrm{b}}$ & $6.57(0.60)^{a, b}$ & $6.88(0.95)^{a, b}$ & $6.47(0.13)^{a, b}$ & $6.77(1.44)^{a, b}$ & $7.24(0.64)^{\mathrm{a}}$ & $7.52(0.78)^{a}$ \\
\hline 0 & $40.08(0.42)^{a, b}$ & $39.76(0.67)^{a, b}$ & $39 \cdot 37(1,24)^{b}$ & $41.50(0.51)^{\mathrm{a}}$ & $41.48(0.34)^{a}$ & $39.22(1.10)^{b}$ & $40,27(0,92)^{a}$ \\
\hline$P$ & $14.7(0.39)^{\mathrm{a}}$ & $14.8(0.53)^{\mathrm{a}}$ & $14.81(0.59)^{\mathrm{a}}$ & $13.41(0.84)^{b}$ & $13.70(0.44)^{b}$ & $14.54(0.19)^{\mathrm{a}}$ & $14.56(0.38)^{a}$ \\
\hline $\mathrm{Ca}$ & $37.09(0.67)^{\mathrm{a}}$ & $36.58(0.58)^{a, b}$ & $36.50(1.14)^{a, b}$ & $35.40(1.52)^{b}$ & $35.59(0.57)^{b}$ & $36.50(0.70)^{a, b}$ & $35.92(0.92)^{b}$ \\
\hline $\mathrm{F}$ & $0.19(0.06)^{b}$ & $0.05(0.04)^{d}$ & $0.11(0.05)^{c}$ & $0.28(0.07)^{\mathrm{a}}$ & $0.01(0.01)^{d}$ & $0.20(0.03)^{b}$ & $0.03(0.02)^{d}$ \\
\hline $\mathrm{Mg}$ & $0.27(0.08)^{\mathrm{a}}$ & $0.21(0.05)^{\mathrm{b}}$ & $0.22(0.06)^{a, b}$ & $0.17(0.04)^{b}$ & $0.20(0.01)^{a, b}$ & $0.23(0.01)^{a, b}$ & $0.21(0.02)^{a, b}$ \\
\hline $\mathrm{Zn}$ & $0.07(0.09)^{\mathrm{c}}$ & $0.23(0.06)^{\mathrm{a}}$ & $0.10(0.07)^{b, c}$ & $0.04(0.06)^{c}$ & $0.22(0.02)^{a, b}$ & $0.03(0.06)^{\mathrm{c}}$ & $0.09(0.08)^{\mathrm{C}}$ \\
\hline $\mathrm{Sr}$ & $0.34(0.04)^{a}$ & $0.10(0.13)^{\mathrm{C}}$ & $0.23(0.04)^{b}$ & $0.38(0.08)^{\mathrm{a}}$ & $0.23(0.04)^{b}$ & $0.21(0.04)^{b}$ & $0.22(0.10)^{b}$ \\
\hline $\mathrm{Na}$ & $0.48(0.17)^{\mathrm{a}}$ & $0.63(0.24)^{a}$ & $0.64(0.23)^{a}$ & $0.57(0.28)^{\mathrm{a}}$ & $0.56(0.03)^{\mathrm{a}}$ & $0.55(0.04)^{\mathrm{a}}$ & $0.60(0.06)^{a}$ \\
\hline $\mathrm{Al}$ & $0.01(0.01)^{b}$ & $0.00(0.00)^{b}$ & $0.01(0.01)^{b}$ & $0.02(0.01)^{a, b}$ & $0.00(0.00)^{b}$ & $0.00(0.00)^{b}$ & $0.03(0.03)^{a}$ \\
\hline Si & $0.30(0.12)^{\mathrm{c}}$ & $0.73(0.27)^{b}$ & $0.73(0.28)^{b}$ & $1.66(0.15)^{\mathrm{a}}$ & $1.08(0.38)^{b}$ & $0.68(0.08)^{b}$ & $0.21(0.05)^{\mathrm{c}}$ \\
\hline$S$ & $0.00(0.00)^{b}$ & $0.09(0.10)^{\mathrm{a}}$ & $0.01(0.02)^{b}$ & $0.00(0.00)^{b}$ & $0.02(0.03)^{a, b}$ & $0.07(0.08)^{\mathrm{a}}$ & $0.02(0.03)^{b}$ \\
\hline $\mathrm{Cl}$ & $0.18(0.06)^{b, c}$ & $0.19(0.08)^{b, c}$ & $0.22(0.07)^{a, b}$ & $0.10(0.04)^{c}$ & $0.15(0.05)^{\mathrm{b}, \mathrm{c}}$ & $0.26(0.03)^{\mathrm{a}}$ & $0.26(0.06)^{a}$ \\
\hline $\mathrm{K}$ & $0.06(0.06)^{\mathrm{a}}$ & $0.05(0.07)^{\mathrm{a}}$ & $0.03(0.05)^{\mathrm{a}}$ & $0.02(0.01)^{a}$ & $0.00(0.00)^{\mathrm{a}}$ & $0.01(0.02)^{\mathrm{a}}$ & $0.05(0.07)^{a}$ \\
\hline $\mathrm{Ti}$ & $0.00(0.00)^{b}$ & $0.00(0.01)^{b}$ & $0.14(0.03)^{a}$ & $0.01(0.01)^{b}$ & $0.01(0.01)^{b}$ & $0.29(0.05)^{\mathrm{a}}$ & $0.00(0.01)^{b}$ \\
\hline $\begin{array}{l}\mathrm{Ca} / \mathrm{P} \\
(\mathrm{mol})\end{array}$ & $1.95(0.05)^{a, b}$ & $1.91(0.06)^{b}$ & $1.91(0.05)^{\mathrm{b}}$ & $2.05(0.22)^{a}$ & $2.01(0.03)^{a, b}$ & $1.94(0.02)^{a, b}$ & $1.91(0.02)^{b}$ \\
\hline
\end{tabular}

\section{Conclusions}


The presentstudy structurally characterized and compared the remineralizing effect and tubules occlusion capabilities of different commerciallyavailable toothpastes and topicalformulations. Every formulation had its unique composition, varying in terms of calcium phosphates content, calcium phosphates to silica ratio, and ion doping. PXRD, FTIR-ATR, and chemical characterizations confirmed that the inorganic water-insoluble fraction of the toothpaste formulations were composed of amorphous silica and HA, consistently with the ingredient list.Results showed that, where present,HA was amorphous and doped with $\mathrm{CO}_{3}{ }^{2-}$ and either $\mathrm{Zn}^{2+}$ or $\mathrm{F}^{-}, \mathrm{Mg}^{2+}$, and $\mathrm{Sr}^{2+}$ ions. Furthermore, the aqueous washing used in the characterization procedures crystallized the active principle of ACP-containing formulations, leading to poorly crystalline HA formation.

The efficacy of the formulations to induce enamel bioremineralization and to occlude dentinal tubules has been investigated morphologically and semiquantitatively by SEM and EDS. All tested formulations, save for reference one, deposited a mineral layer on the surface of the specimens that occluded dentinal tubules andremineralized eroded enamel. For the latter substrate, a new crystalline phase was grown in continuity with the native one. Epitaxial growth of nanocrystallites was thus identified and was most pronounced in BT and BM. Regarding dentine substrate, all mousse formulations showed complete occlusion of dentinal tubules, while toothpastes showed occlusion of most of the exposed tubules.However, the deposited layer, having a thickness of about 200 to $300 \mathrm{~nm}$ independently of the tested formulation, was mainly made by spherical nanoparticles rather than HA nanocrystallites, suggesting the need of enamel prisms or an additional scaffolding agent to achieve epitaxial growth. Therefore, it can be concluded that all tested formulations showed remineralizing effects thanks to the deposition ofbiomimetic, ion-substituted HA (chemically similar to biogenic $\mathrm{HA}$ ) on demineralized enamel and exposed dentinal tubules. The null hypothesis can thus be rejected. A direct correlation between the diameter/density of open dentinal tubules and teeth hypersensitivity is well reported in the literature $[37,38]$. Although the data presented in this work are in vitro results, it can be speculated that the high degree of dentinal tubules occlusion exerted by the tested formulations could lead to a desensitizing clinical effect. Additional investigations need to be carried out to clinically study the effect of the formulations on enamel and dentin substratesin the longterm. The use of organic scaffolding systems such as self-assembly peptides, or poly ascorbic acid, may also be tested to improve bioremineralization processes particularly on the dentine substrate.

\section{Methods}

Materials. The tested toothpastes and topical formulations and their composition as specified by the manufacturerare presented in Table 1. Modified Dulbecco's phosphate-buffered saline (PBS, without $\mathrm{CaCl}_{2}$ and $\mathrm{MgCl}_{2}$ ), orthophosphoric acid $\left(\mathrm{H}_{3} \mathrm{PO}_{4} 85 \mathrm{wt} \%\right.$ in $\left.\mathrm{H}_{2} \mathrm{O}\right)$, hydrochloric acid $\left(\mathrm{HCl} 37 \mathrm{wt} \%\right.$ in $\left.\mathrm{H}_{2} \mathrm{O}\right)$, and hydrofluoric acid $\left(\mathrm{HF} 40 \mathrm{wt} \%\right.$ in $\left.\mathrm{H}_{2} \mathrm{O}\right)$ were purchased from Sigma Aldrich (St. Luis, MO, USA). All the solutions were prepared with ultrapure water as well as washing procedures (18.2 $\mathrm{M} \Omega \times \mathrm{cm}, 25^{\circ} \mathrm{C}$, Arium® pro, Sartorius, Göttingen, Germany).

Sample Preparation. An aliquot of each toothpaste was freeze-dried overnight at $-50{ }^{\circ} \mathrm{C}$ under a vacuum of $3 \mathrm{mbar}$ and then weighted to estimate its water content. Each toothpaste was then washed with ultrapure water to separate the water-insoluble fraction. A total of $5 \mathrm{~g}$ of each toothpaste was dispersed in $150 \mathrm{~mL}$ of ultrapure water. Then, three repeated rinses with water were performed, each followed by centrifugation at 10,000 rpm for $5 \mathrm{~min}$. The compounds were freeze-dried overnight, ground, and sieved with a $50 \mu \mathrm{m}$ sieveto achieve uniform granulometry. The resulting dried powders were weighted to quantify the water-insoluble fraction of the toothpaste. Then, an aliquot was dissolved in a $6 \mathrm{wt} \% \mathrm{HNO}_{3}$ solution to collect the acidinsoluble fraction. The latter fraction was collected by centrifugation (10,000 rpm for $5 \mathrm{~min})$, freeze-dried overnight, and then weighted [17].

Structural Characterization Powder X-ray diffraction (PXRD) patterns of the water-insoluble and acid-insoluble fractions of the products were measured in the angular region from 10 to $60^{\circ}(2 \theta)$ with a step size of $0.02^{\circ}$ and a collection time of $0.5 \mathrm{~s}$. Cu Ka X-rays $(\lambda=1.5418 \AA$ ) were generated at $40 \mathrm{kV}$ and $40 \mathrm{~mA}$. The PXRD patterns were collected on a D8 Advance diffractometer (Bruker, Karlsruhe, Germany) equipped with a Lynx-eye detector.

Fourier transform infrared (FT-IR) spectra of the freeze-dried products, the water-insoluble fractions, and the acid-insoluble fractions of the products were collected with a Nicolet iS5 instrument (Thermo Fisher Scientific Inc., Waltham, MA, USA) 
equipped with iD7 attenuated total reflectance (ATR) accessory.

Compositional Analysis. Quantification of $\mathrm{Mg}^{2+}, \mathrm{Sr}^{2+}$, and $\mathrm{Zn}^{2+}$ in the whole products and their water-insoluble fractions was performed with an Agilent 5100 inductively-coupled plasma optical emission spectrometer (ICP-OES, Agilent Technologies, Santa Clara, CA, USA). Samples were prepared by dissolving $100 \mathrm{mg}$ of the whole product orwater-insoluble fraction in $50 \mathrm{~mL}$ of a $0.8 \mathrm{wt} \% \mathrm{HF}$ solution.

The quantification of fluorine in the whole formulations was performed with an ion-selective electrode(ISE) for fluoride (Intellical ISEF121, Hach Lange, Loveland, CO, USA). A total of $6 \mathrm{~mL}$ of an aqueous dispersion of the product $\left(0.1 \mathrm{~g} \mathrm{~mL}^{-1}\right)$ was mixed with an equal volume of $37 \mathrm{wt} \% \mathrm{HCl}$ and left to react for $1 \mathrm{~h}$ at $50^{\circ} \mathrm{C}$ to dissociate fluoride ions completely[36]. Afterward, the acid-insoluble residue was removed by centrifugation (14,000 rpm, 3 minutes), and the supernatant was analyzed using the protocol suggested by the instrument's manufacturer.

An aliquot of the whole formulation $(1 \mathrm{~g})$ was also dried overnight in the vacuum bell, then in the observation chamber of a tabletop SEM and observed using energy-dispersive X-ray spectroscopy (EDS). The analysis was performed using a tabletop scanning electron microscope (TM4000Plus,Hitachi, Schaumburg, IL, USA) equipped with an EDS probe (Q75, Bruker, Berlin, Germany). Specimens were observed in surface-charge reduction mode without sputter-coating, using an accelerating voltage of $15 \mathrm{kV}$. Three randomly selected fields were acquired for each specimen (three aliquots per each formulation from three different tubes) at 300x magnification in full-frame mode using an acquisition time of $150 \mathrm{~s}$ [35].Acquired data represented the elemental composition of the $\approx 1 \mu \mathrm{m}$ superficial layer (depth of sampling depends on the atomic number of sampled elements, see Figure 6).

In Vitro Evaluation of Remineralization and Dentinal Tubules Occlusion. A total of 18 sound human molar teeth extracted for clinical reasons were obtained and used for the in vitro experiments (Oral Surgery Unit, Department of Biomedical, Surgical and Dental Sciences, Milan, Italy). The Institutional Review Board of the University of Milan approved the use of the teeth (protocol SALTiBO-2017). Each donor signed informed consent in a written form. All in vitro experiments were performed in accordance with the Declaration of Helsinki, updated by the World Medical Association in 2013.

Horizontal sections of the teeth specimens were obtained under constant water cooling using a low-speed saw(Isomet 1000, Buehler, Lake Bluff, IL, USA). Cuts were performed at two depth levels in order to section the root $2 \mathrm{~mm}$ apical to the cementoenamel junction and to obtain flat enamel $(n=18)$ or dentin $(n=18)$ surfaces (Figure 7A). Then, on both dentine and enamel sections,two perpendicular $0.5 \mathrm{~mm}$-deep notches were made on the top surface of each specimen to mark four areas using a low-speed diamond disc (Horico, Berlin, Germany, Figure 7B). All surfaces were polished using silicon carbide paper (600 and 1200 grit), and the surfaces were etched with a $37 \mathrm{wt} \% \mathrm{H}_{3} \mathrm{PO}_{4}$ solution for $30 \mathrm{~s}$, followed by extensive rinsing with water[17].

The toothpastes were soft-brushed for 3 min using disposable microbrushes (Microbrush ${ }^{\circledR}$, Microbrush International, Grafton, WI, USA), then they were rinsed with ultrapure water for $1 \mathrm{~min}$. Each toothpaste was applied on a single section of a specimen, either enamel $(n=18)$ or dentine $(n=18)$, to test enamel remineralization and dentinal tubule occlusion, respectively. This treatment was repeated three times each day for one week. Specimens were stored in fresh PBS at $37^{\circ} \mathrm{C}$ between treatments.

Demineralized specimens (three for enamel and three for dentin substrates) were used as negative controls and brushed with PBS.

After the last treatment, all specimens were left to dry overnight in a desiccator. Then,the conductive tape was used to fix them on stubs and storedin a vacuum bell for five hours. After that, they were sputter-coated with gold (Polaron Sputter Coater E5100, Polaron Equipment, Watford, Hertfordshire, UK) and observed with an SEM (JSM 840A, JEOL, Tokyo, Japan) in secondary electrons mode at an acceleration voltage of $10 \mathrm{kV}$. For each specimen and toothpaste treatment, four randomly selected fields were acquiredat magnifications ranging from 500x to 40000x. The enamel remineralization and dentinal tubule 
occlusion ability of the tested formulations were compared to a conventional fluoride-containing toothpaste (reference CT, Table 1)) that is considered a standard treatment in the prevention of demineralization.

Elemental composition of the specimen surface. EDS analysis was performed as previously specified on treated specimens after vacuum-drying but before sputter-coating.Surface-charge reduction modeand an accelerating voltage of $15 \mathrm{kV}$ were used. Three randomly selected fields were acquired for each enamel specimen and treatment at 300× magnification.

Statistical Analysis. All experiments regarding the structural characterization and compositional analysis were performed in triplicate and repeated at least three times. Data are reported throughout the text as means \pm 1 standard deviation. To compare the presence of each element between the toothpaste treatments, EDS data were analyzed using ANOVA and Tukey's HSD post-hoc test, setting the significance level to $p<0.05$. Prior verification of normality of distribution and homoscedasticity was performed by Shapiro Wik's and Levène's tests, respectively $(p<0.05)$.

\section{Declarations}

\section{Acknowledgements}

The authors are grateful to Dr. Massimo Tagliaferro and Nanovision S.R.L. for providing the tabletop SEM-EDS platform.

\section{AuthorContributions}

Conceptualization,A.C.I., M.I., andL.D.E.; structural characterization, compositional analysis, and the in vitro remineralization tests, L.D.E. and A.C.I.; teeth specimens collection and preparation, A.C.I.; SEM-EDS, A.C.I.; supervision, E.B. and M.I.; writingoriginal draft preparation, A.C.I.,and L.D.E.; writing-review and editing, E.Band M.I. All authors reviewedthemanuscript.

Competing Interests: The authors declare no competing interests.

Publisher'snote: Springer Nature remains neutral with regard to jurisdictional claims in published maps and institutional affiliations.

Open Access This article is licensed under a Creative Commons Attribution 4.0 International License, which permits use, sharing, adaptation, distribution, and reproduction in any medium or format, as long as you give appropriate credit to the original author(s) and the source, provide a link to the Creative Commons license, and indicate if changes were made. The images or other third-party material in this article are included in the article's Creative Commons license unless indicated otherwise in a credit line to the material. If material is not included in the article's Creative Commons license and your intended use is not per- mitted by statutory regulation or exceeds the permitted use, you will need to obtain permission directly from the copyright holder. To view a copy of this license, visit http://creativecommons.org/licenses/by/4.0/.

(c) The Author(s) 2021

\section{References}

1. García-Godoy, F., \& Hicks, M. J. Maintaining the integrity of the enamel surface: the role of dental biofilm, saliva and preventive agents in enamel demineralization and remineralization. The Journal of the American Dental Association139, 25S-34S (2008).

2. Caries, W. I. Dental caries: etiology, clinical characteristics, risk assessment, and management. Sturdevant's Art \& Science of Operative Dentistry-E-Book40 (2017).

3. Marsh, P. D. Dental plaque as a biofilm: the significance of $\mathrm{pH}$ in health and caries. Compendium of continuing education in dentistry (Jamesburg, NJ: 1995)30(2), 76-8 (2009).

4. Gewargis, J. The biochemical basis of dental caries in action.Dentistry36, 5 (2017).

Page $12 / 20$ 
5. Lechien, J. R., Calvo-Henriquez, C., Chiesa-Estomba, C. M., Barillari, M. R., Trozzi, M., Meucci, D., ... \& Saussez, S. Reflux and dental disorders in the pediatric population: A systematic review. International Journal ofPediatry and Otorhinolaryngology136, 110166 (2020).

6. Tinanoff, N. Dental caries. InPediatric Dentistry169-179 (2019).

7. Farooq, I., \& Bugshan, A. The role of salivary contents and modern technologies in the remineralization of dental enamel: a narrative review.F1000Research 9 (2020).

8. Clift, F. Artificial methods for the remineralization of hydroxyapatite in enamel.Materials Today Chemistry21, 100498 (2021).

9. Shaheen, M., Aswin, S., \& Thomas, A. J. Recent advances in enamel and dentin remineralization. International Journal of Oral Care Research 9(2), 63 (2021).

10. Iafisco, M., Degli Esposti, L., Ramírez-Rodríguez, G. B., Carella, F., Gómez-Morales, J., lonescu, A. C., ... \& Delgado-López, J. M. Fluoride-doped amorphous calcium phosphate nanoparticles as a promising biomimetic material for dental remineralization. ScientificReports8(1), 1-9 (2018).

11. Palmer, L. C., Newcomb, C. J., Kaltz, S. R., Spoerke, E. D., \& Stupp, S. I.. Biomimetic systems for hydroxyapatite mineralization inspired by bone and enamel. Chemical Reviews 108(11), 4754-4783 (2008).

12. Lacruz, R. S., Habelitz, S., Wright, J. T., \& Paine, M. L. Dental enamel formation and implications for oral health and disease.Physiological Reviews 97(3), 939-993 (2017).

13. Fernandez-Ferrer, L., Vicente-Ruiz, M., Garcia-Sanz, V., Montiel-Company, J. M., Paredes-Gallardo, V., Almerich-Silla, J. M., \& Bellot-Arcis, C. Enamel remineralization therapies for treating postorthodontic white-spot lesions: A systematic review. The Journal of the American Dental Association149(9), 778-786(2018).

14. Carella, F., Degli Esposti, L., Adamiano, A., lafisco, M. The use of calcium phosphates in cosmetics, state of the art and future perspectives. Materials14(21), 6398 (2021).

15. Maguire, A. ADA clinical recommendations on topical fluoride for caries prevention. Evidence-based dentistry15(2), 3839(2014).

16. Weyant, R. J., Tracy, S. L., Anselmo, T. T., Beltrán-Aguilar, E. D., Donly, K. J., Frese, W. A., Hujoel, P.P., lafolla, T., Kohn, W., Kumar, J.,\& Levy, S.M.Topical fluoride for caries prevention. The Journal of the American Dental Association144(11), 12791291(2013).

17. Degli Esposti, L., Ionescu, A. C., Brambilla, E., Tampieri, A., \& lafisco, M. Characterization of a Toothpaste Containing Bioactive Hydroxyapatites and In Vitro Evaluation of Its Efficacy to Remineralize Enamel and to Occlude Dentinal Tubules.Materials13(13), 2928(2020).

18. Roveri, N., Battistella, E., Bianchi, C. L., Foltran, I., Foresti, E., lafisco, M., Lelli, M., Naldoni, A., Palazzo, B.\& Rimondini, L. Surface enamel remineralization: biomimetic apatite nanocrystals and fluoride ions different effects. Journal of Nanomaterials2009(2009).

19. Robinson, C. et al. Subunit Structures in Hydroxyapatite Crystal Development in Enamel: Implications for Amelogenesis Imperfecta. Connective Tissue Research 44, 65-71 (2003).

20. Li, J., Xie, X., Wang, Y., Yin, W., Antoun, J. S., Farella, M., \& Mei, L. Long-term remineralizing effect of casein phosphopeptide-amorphous calcium phosphate (CPP-ACP) on early caries lesions in vivo: a systematic review.Journal of Dentistry42(7), 769-777(2014).

21. Saravanapavan, P., \& Hench, L.L. Mesoporous calcium silicate glasses. I. Synthesis. Journal of non-crystalline solids318, 1-13(2003).

22. Hughes,J.M., Cameron, M.,\&Crowley,K.D. Structural variations in natural F, OH, and $\mathrm{Cl}$ apatites.American Mineralogist74, 870-876(1989).

23. Iafisco, M.; Ramirez-Rodriguez, G.B.; Sakhno, Y., Tampieri, A., Martra, G., Gomez-Morales, J., \& Delgado-Lopez, J.M. The growth mechanism of apatite nanocrystals assisted by citrate: Relevance to bonebiomineralization. CrystEngComm17, 507-511 (2015). 
24. Anderson, D., \& Smith, A.L. Analysis of Silicones. Wiley-Interscience: New York, NY, USA (1974).

25. Antonakos, A., Liarokapis, E., Leventouri, T. Micro-Raman and FTIR studies of synthetic and natural apatites. Biomaterials28, 3043-3054(2007).

26. Miller, F. A.,\& Wilkins, C. H. Infrared spectra and characteristic frequencies of inorganic ions. Analytical chemistry 24 , 1253-1294 (1952).

27. Yu, J. C., Zhang, L., Zheng, Z., \& Zhao, J. Synthesis and characterization of phosphated mesoporous titanium dioxide with high photocatalytic activity. Chemistry of Materials15(11), 2280-2286(2003).

28. González-Cabezas, C., \& Fernández, C. E. Recent advances in remineralization therapies for caries lesions. Advances in dental research29(1), 55-59(2018).

29. Featherstone, J. D. B., \& Nelson, D. G. A. The effect of fluoride, zinc, strontium, magnesium and iron on the crystalstructural disorder in synthetic carbonated apatites. Australian Journal of Chemistry33(11), 2363-2368(1980).

30. Liu, Y. C., Lee, Y. T., Huang, T. C., Lin, G. S., Chen, Y. W., Lee, B. S., \& Tung, K. L. In Vitro Bioactivity and Antibacterial Activity of Strontium-, Magnesium-, and Zinc-Multidoped Hydroxyapatite Porous Coatings Applied via Atmospheric Plasma Spraying. ACS Applied Bio Materials4(3), 2523-2533(2021).

31. Ionescu, A. C., Cazzaniga, G., Ottobelli, M., Garcia-Godoy, F., \& Brambilla, E. Substituted Nano-Hydroxyapatite toothpastes reduce biofilm formation on enamel and resin-based composite surfaces. Journal of Functional Biomaterials11(2), 36(2020).

32. Gurunathan, D., Somasundaram, S., \& Kumar, S. A. Casein phosphopeptide-amorphous calcium phosphate: a remineralizing agent of enamel.Australian dental journal57(4), 404-408(2012).

33. Safarzadeh, M., Ramesh, S., Tan, C. Y., Chandran, H., Noor, A. F. M., Krishnasamy, S., \& Alengaram, U. J. Effect of multi-ions doping on the properties of carbonated hydroxyapatite bioceramic. Ceramics Internationa/45(3), 3473-3477(2019).

34. Reger, N. C., Bhargava, A. K., Ratha, I., Kundu, B., \& Balla, V. K. Structural and phase analysis of multi-ion doped hydroxyapatite for biomedical applications. Ceramics Internationa/45(1), 252-263(2019).

35. Ionescu, A. C., Comba, A., Brambilla, E., Ilie, N., Breschi, L., Cadenaro, M., \& Scotti, N. Influence of Curing Time on the Microbiological Behavior of Bulk-Fill Nanohybrid Resin Composites. Polymers13(17), 2948(2021).

36. Guimarães, I.C., Rezende, C.C., da Silva, J.A.F.,\&de Jesus, D.P. Simultaneous determination of free fluoride and monofluorophosphate in toothpaste by capillary electrophoresis with capacitively coupled contactless conductivity detection. Talanta78, 1436-1439 (2009).

37. Yoshiyama, M.; Masada, J.; Uchida, A., \& Ishida, H. Scanning electron microscopic characterization of sensitive vs. insensitive human radicular dentin. Journal of Dental Research68, 1498-1502 (1989).

38. Berg, C., Unosson, E., Riekehr, L., Xia, W., Engqvist, H. Electron microscopy evaluation of mineralization on peritubular dentin with amorphous calcium magnesium phosphate microspheres. Ceramics International46, 19469-19475 (2020).

\section{Figures}



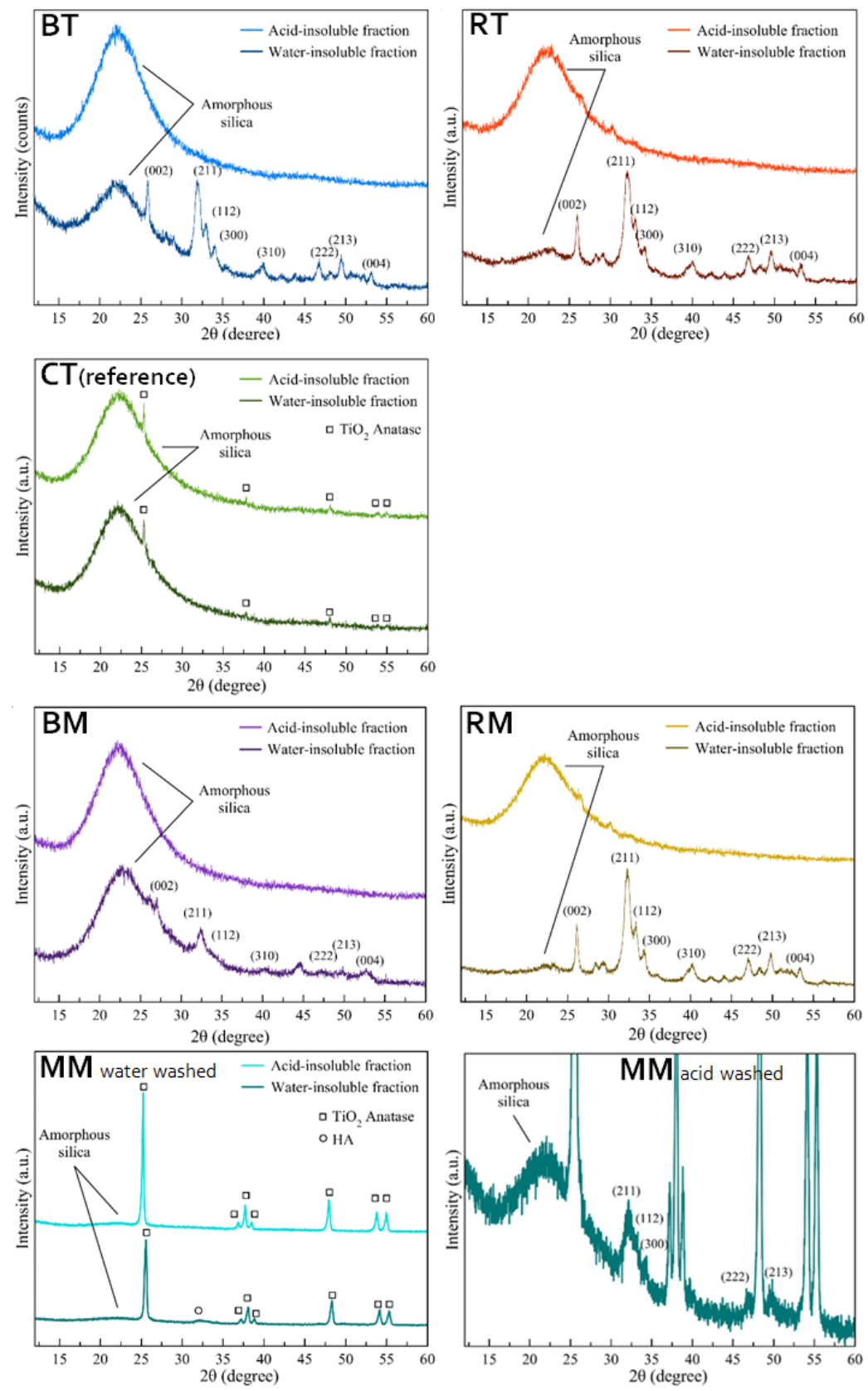

Figure 1

PXRD patterns of the tested formulations 
BT

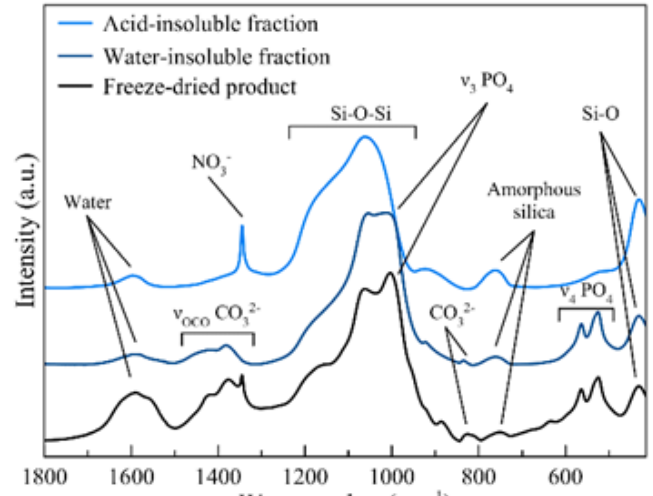

\section{CT (reference) avenumber $\left(\mathrm{cm}^{-1}\right)$}

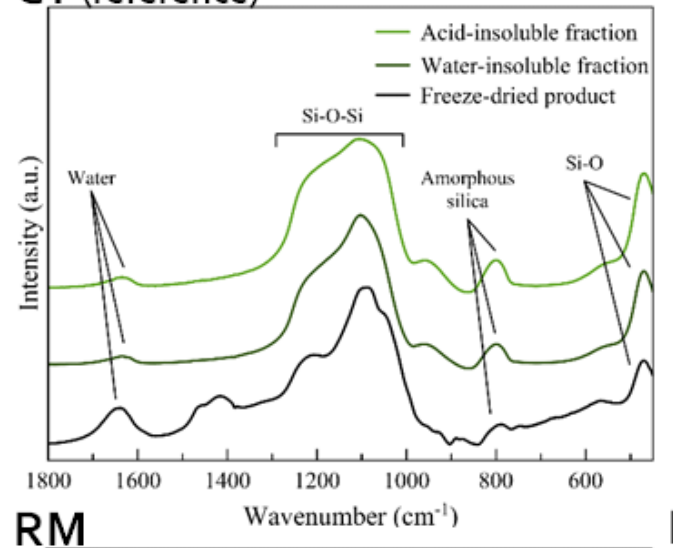

\section{RM}

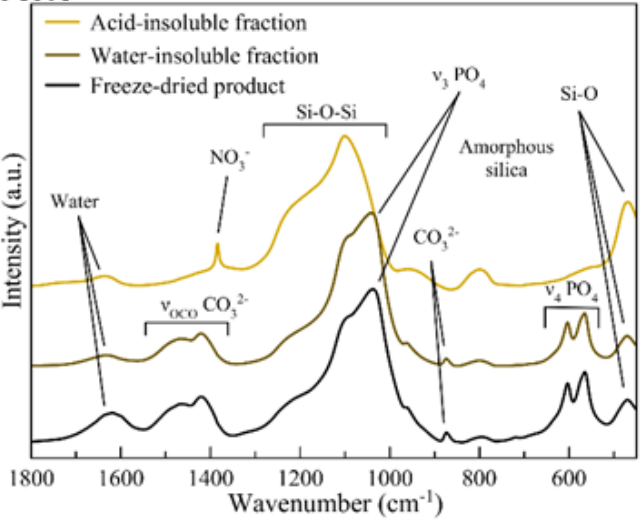

RT

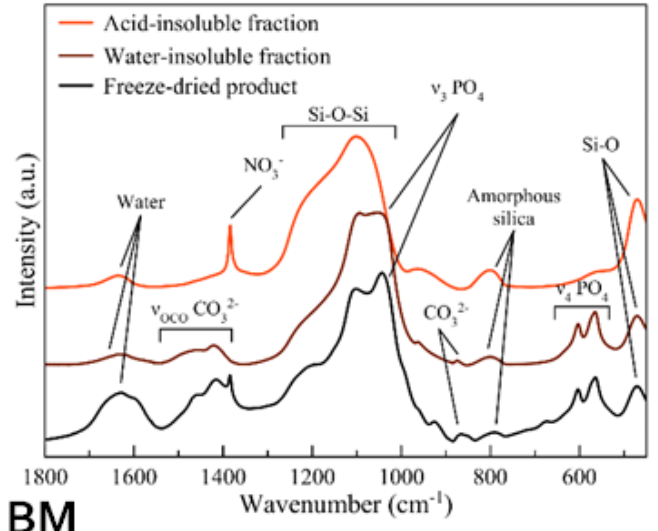

\section{BM}

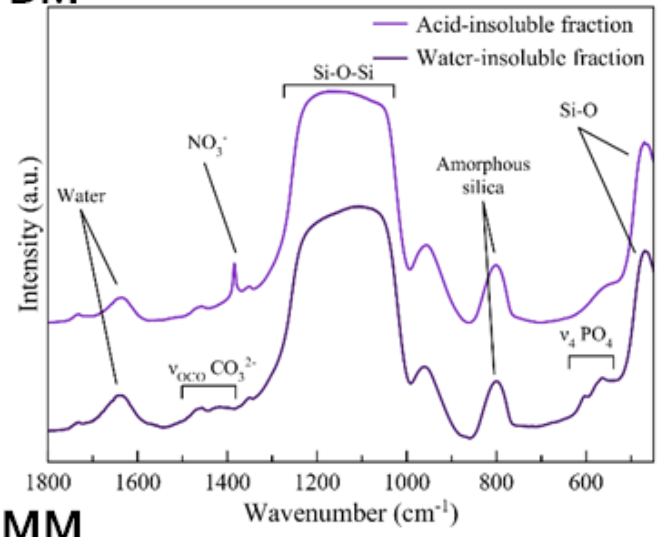

Figure 2

FT-IR spectra of the tested formulations. 


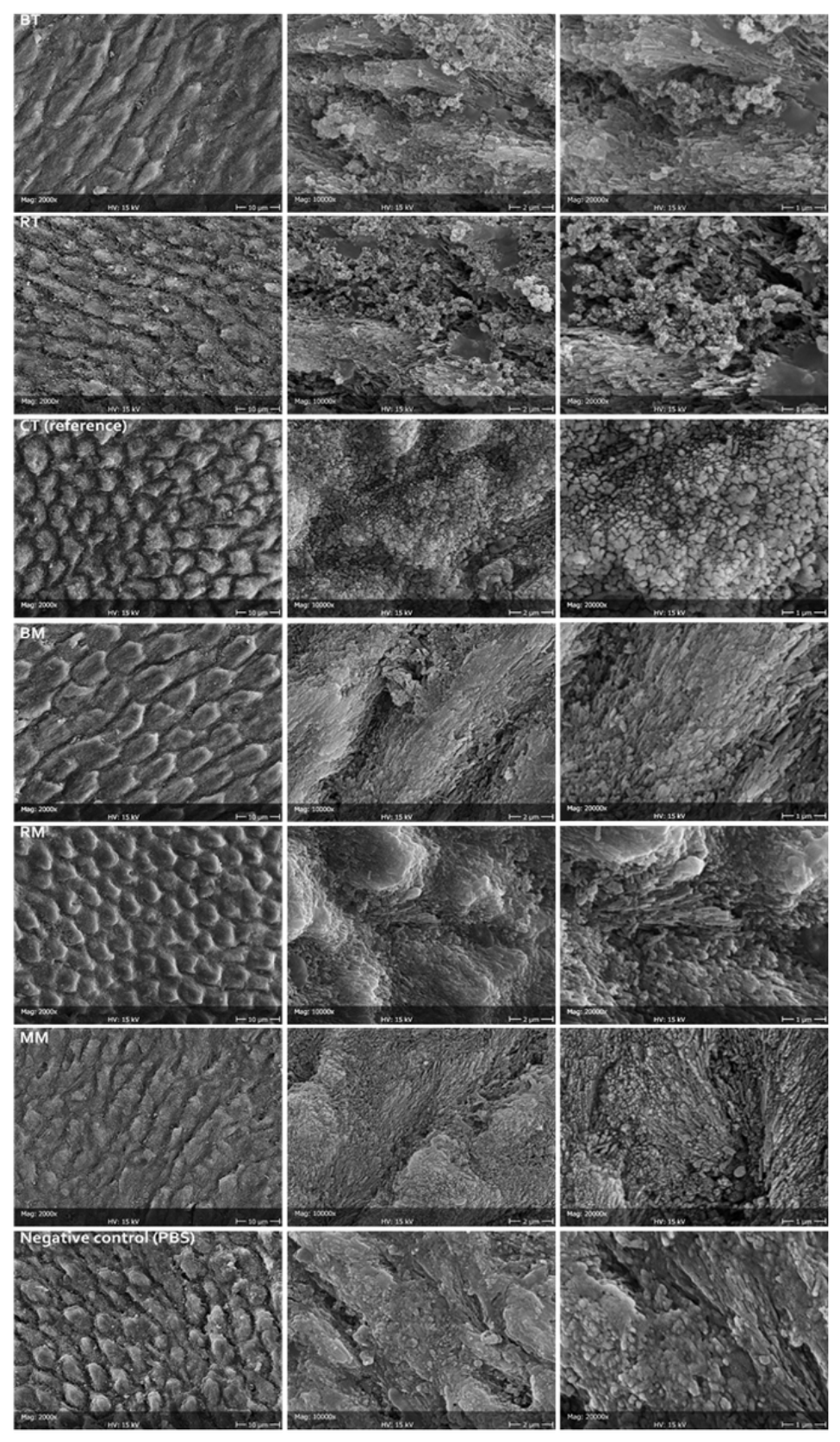

\section{Figure 3}

Representative micrographs at different magnifications of the enamel surface after treatment with the tested and reference formulations, compared to the negative control (demineralized surface stored in PBS). 


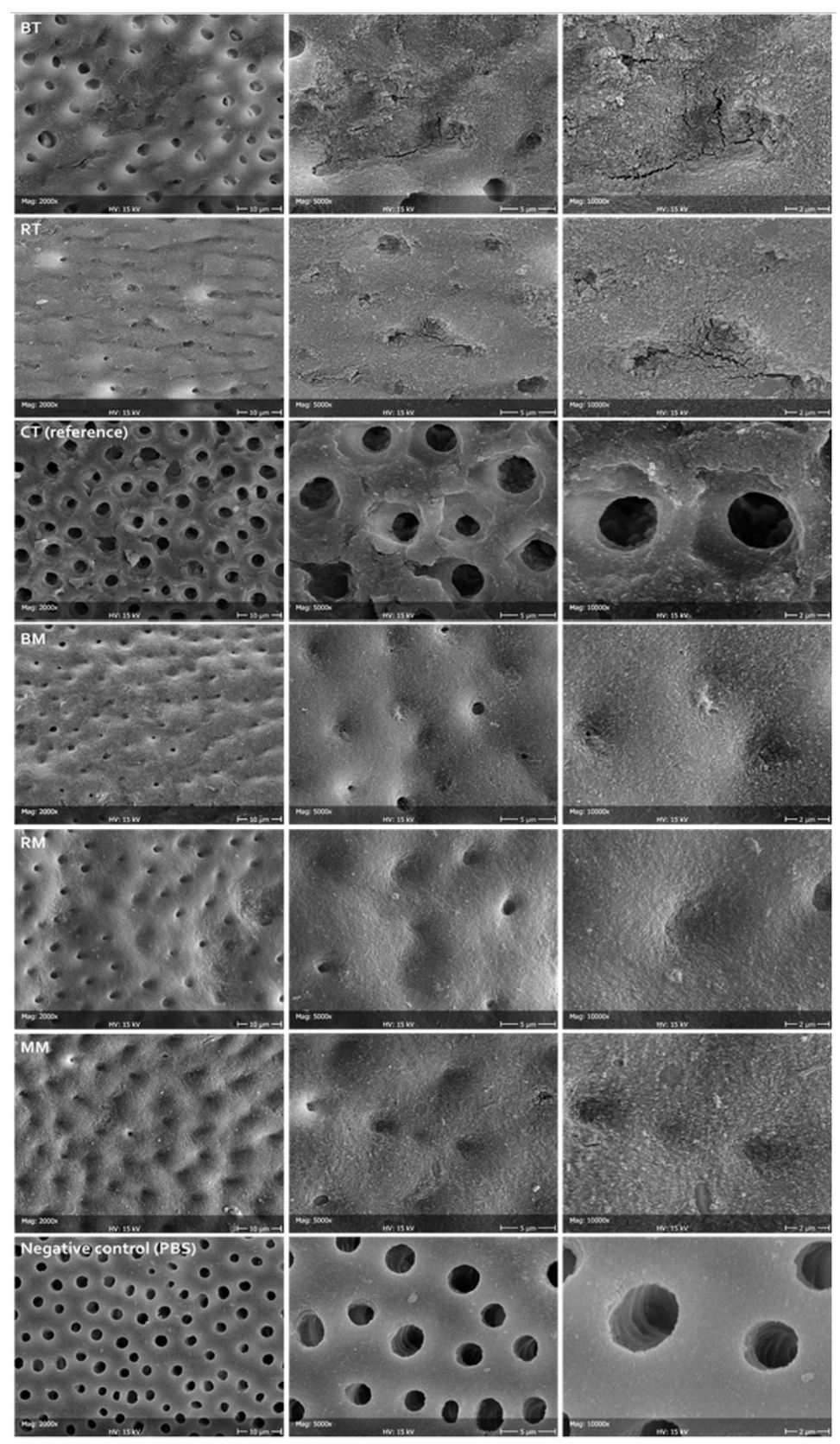

\section{Figure 4}

Representative micrographs at different magnifications of the dentine surfaces after treatment with test and reference formulations, compared to the negative control (demineralized surface stored in PBS). Open tubules can be clearly seen that were closed in a variable percentage depending on the tested formulation. In general, mousses provided betterobliteration (increased layer homogeneity) of the tubules than the toothpastes. 

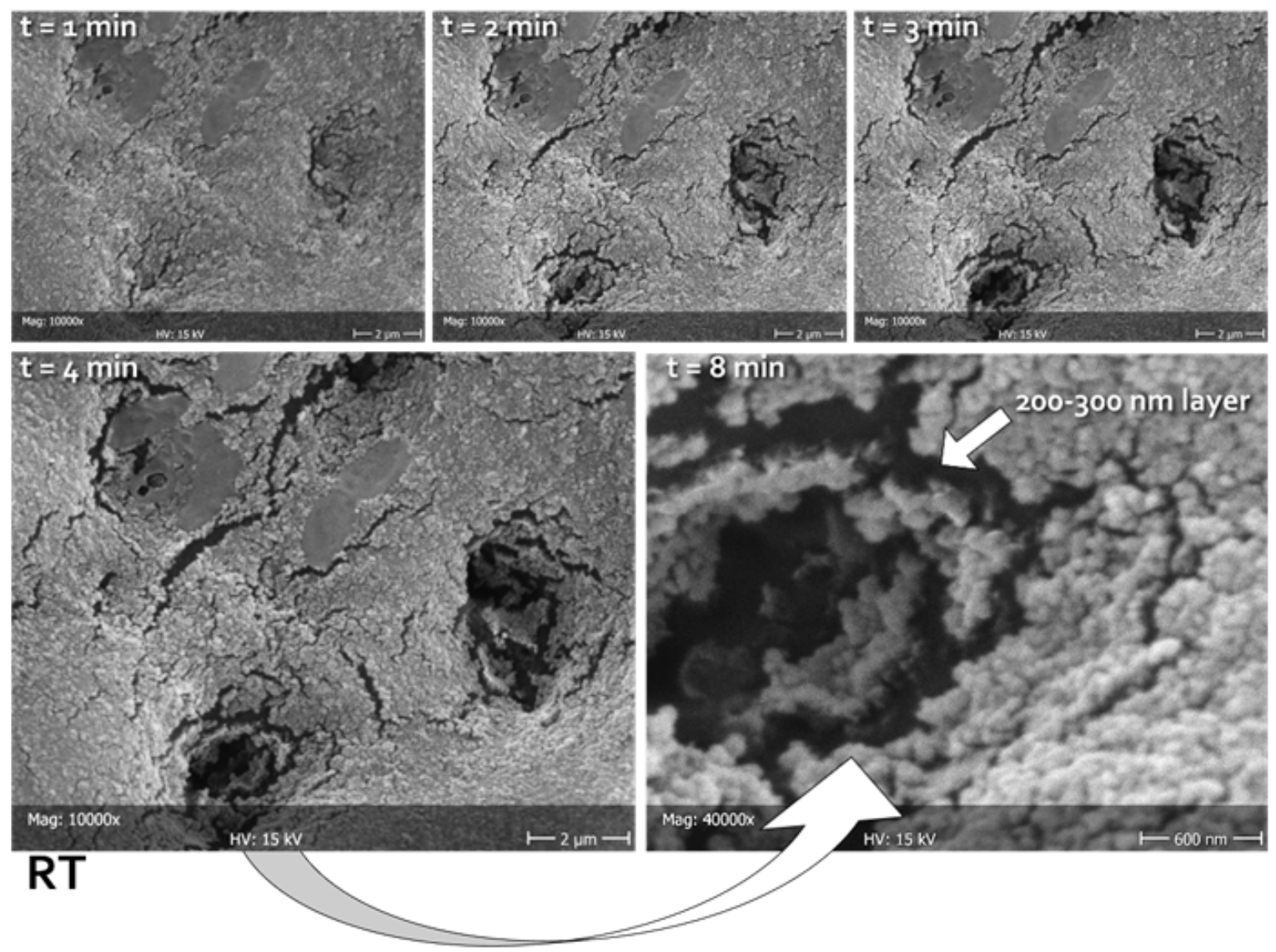

\section{Figure 5}

Representative micrographs of the same area (in this case belonging to RT),scanned at different times, focusing the electron beam on the opening of tubules, thus heating the carbon-rich collagen structures underneath and disrupting the mineralized material obliterating the lumen. In this way, it was possible to measure the thickness of the deposited layer. The latter can be clearly seen as constituted by a homogeneous assembly of spherical nanoparticles. The absence of exposed HA prisms in this substratum did not allow for epitaxial growth, therefore no HA nanocrystals could be identified, independently from the tested formulations. It can be speculated that, considering the treatment time that was allowed in this study (one week) the tested formulations might need to incorporate a scaffod in order to be able to grow organized structures on the dentinal substrate.

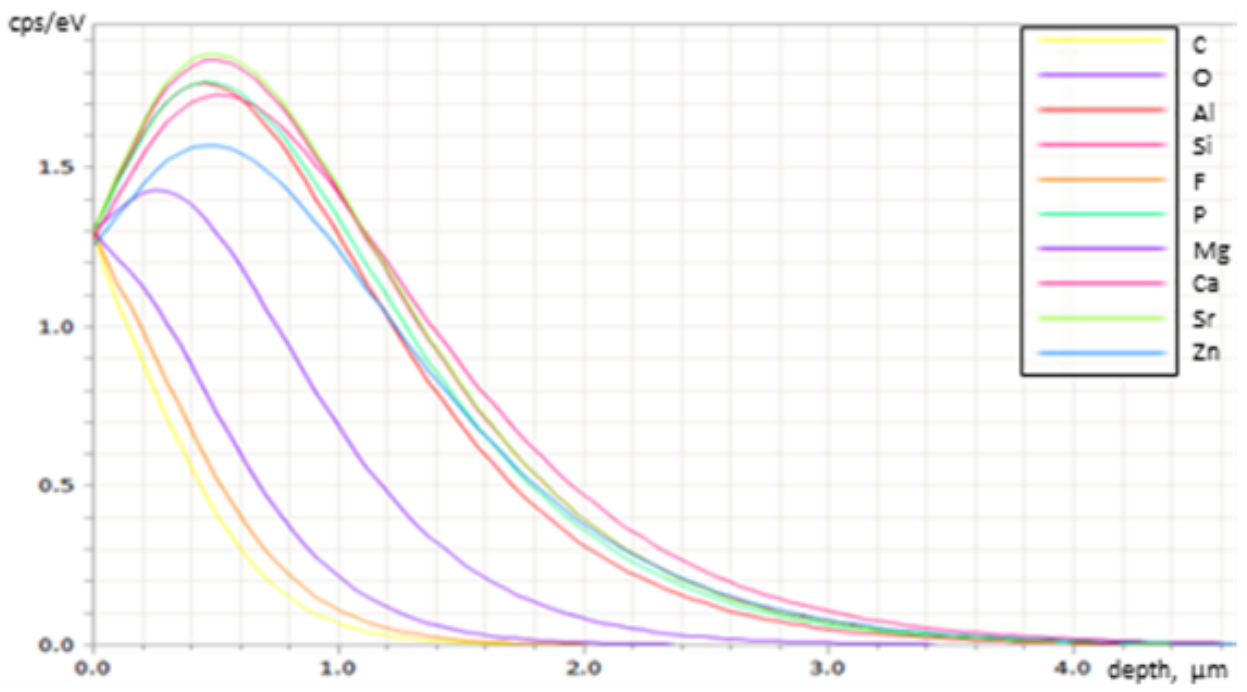

Figure 6 
Energy-dispersive X-ray spectroscopy (EDS) spectra of depth interaction at $15 \mathrm{KV}$ electron accelerating voltage depending on the different elements. While carbon, oxygen, and fluoride signals originate from a very superficial layer (most of the signal comes from the first $600 \mathrm{~nm}$ ), the information of all other elements comes from a much thicker layer where most information comes from the first $1200 \mathrm{~nm}$. This distribution has to be kept in mind when analyzing the elemental compositions of the remineralized layers having a thickness of 200 to $300 \mathrm{~nm}$ (Figure 5).
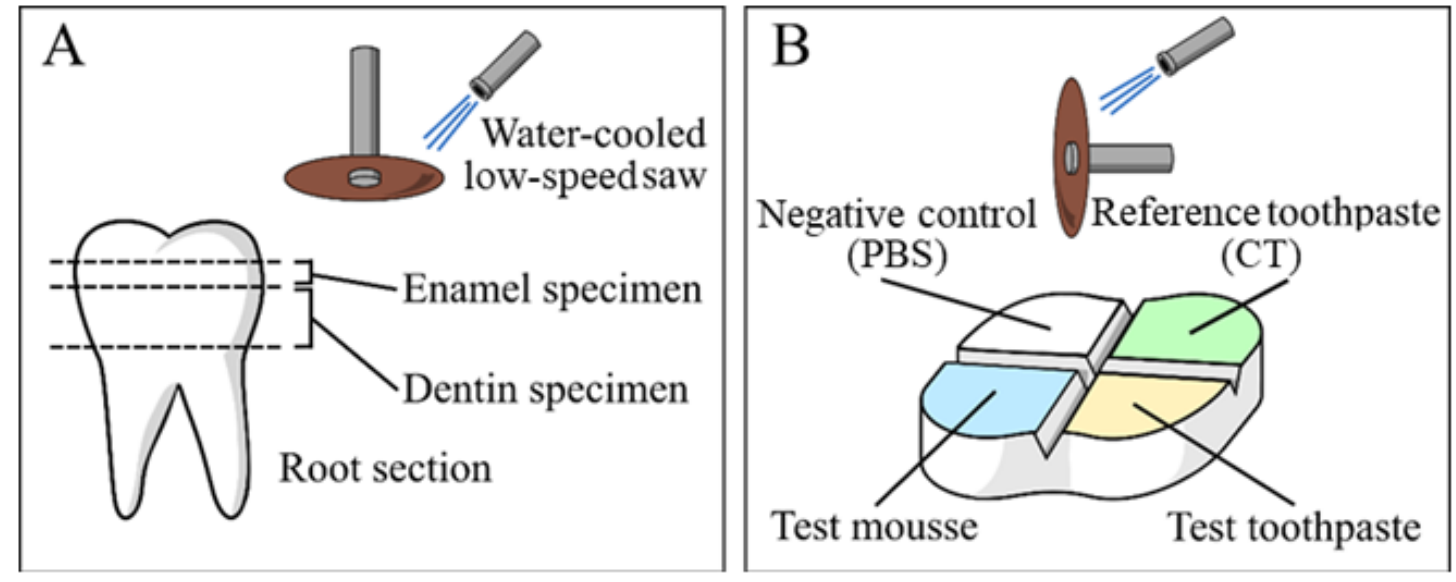

Figure 7

Schematic representation of specimen preparation: (A) horizontal sections of the tooth exposing enamel and dentin and (B) delimitation of control and treatment regions by notches made using the diamond disc. 